\title{
Longitudinal determinants of mental health treatment-seeking by US soldiers
}

\author{
Amy B. Adler, Thomas W. Britt, Lyndon A. Riviere, Paul Y. Kim and Jeffrey L. Thomas
}

\section{Background}

Studies with members of the armed forces have found a gap between reports of mental health symptoms and treatmentseeking.

\section{Aims}

To assess the impact of attitudes on treatment-seeking behaviours in soldiers returning from a combat deployment.

\section{Method}

A sample of 529 US soldiers were surveyed 4 months (time 1) and 12 months (time 2) post-deployment. Mental health symptoms and treatment-seeking attitudes were assessed at time 1; reported mental healthcare visits were assessed at time 2 .

\section{Results}

Factor analysis of the total time 1 sample revealed four attitude factors: professional concerns, practical barriers, preference for self-management and positive attitudes about treatment. For the subset of 160 soldiers reporting a mental health problem at time 1, and controlling for mental health symptom severity, self-management inversely predicted treatment-seeking; positive attitudes were positively related.

\section{Conclusions}

Results demonstrate the importance of broadening the conceptualisation of barriers and facilitators of mental healthcare beyond stigma. Techniques and delivery models emphasising self-care may help increase soldiers' interest in using mental health services.

\section{Declaration of interest \\ None.}

\section{Copyright and usage}

(c) The Royal College of Psychiatrists 2015.
Combat deployments often lead to an increase in mental health problems that are uniquely multifaceted and specific to a military population, ${ }^{1}$ yet studies have identified that members of the armed forces are reluctant to seek mental healthcare. ${ }^{2}$ Two reasons for the gap between mental health problems and treatment-seeking may be concern about stigma and practical organisational barriers associated with mental healthcare. ${ }^{2-4}$ For example, several studies have demonstrated that individuals reporting more mental health problems also report greater concerns about stigma. ${ }^{2,3,5}$ Although there is a rationale for making a link between stigma and treatment-seeking, ${ }^{6}$ few studies have assessed whether attitudes about stigma and barriers to care actually drive treatment-seeking. In a notable exception, Jones et al found that stigma concerns did not account for military medical treatment-seeking in military personnel; however, seeking help from friends was associated with greater stigma concerns. ${ }^{7}$

Recent studies have identified that other attitudes may need to be considered. For example, in the US National Comorbidity Survey, ${ }^{8}$ the most commonly endorsed reason for not seeking treatment was 'Wanted to handle problem on own', or a preference for self-reliance or self-management. This preference has been found in other studies as well. In a study of members of the Canadian armed forces, a preference for self-management was cited as one of the most common barriers to treatment and was the third most commonly endorsed suggestion for improving access to mental healthcare. ${ }^{9}$ Similarly, a study of soldiers withdrawing from treatment for post-traumatic stress disorder (PTSD) found that the most frequently cited reason was a preference for soldiers to take care of problems on their own. ${ }^{10}$ In a cross-sectional study, Kim et al also found that a factor combining negative attitudes towards mental healthcare and a preference for handling problems oneself correlated with treatment-seeking, but a factor reflecting concerns about stigma did not. ${ }^{11}$ Building on these and other results, ${ }^{12,13}$ our study used a longitudinal design to assess the impact of attitudes on seeking mental healthcare, while trying to differentiate the negative attitudes factor reported by Kim et al. ${ }^{11}$ We predicted that a preference for managing one's own mental health symptoms would be inversely associated with treatment-seeking over time, whereas positive attitudes toward treatment would be positively associated.

\section{Method}

Study participants were active-duty US soldiers in a brigade combat team from a large Midwestern post. These were full-time soldiers (not reservists or National Guard personnel) assigned to their home unit. The brigade had recently experienced a 12-month combat deployment to Afghanistan. Soldiers were surveyed 4 months after the brigade returned from the deployment (time 1) in July 2011 and again 12 months later (time 2) in August 2012. Participants provided informed consent prior to enrolment under a protocol approved by the Walter Reed Army Institute of Research institutional review board, and over $90 \%$ of the soldiers who attended the recruitment briefings at both time points consented to participate. The time 1 sample consisted of 2887 personnel, of whom 529 completed the time 2 assessment (18\% of the time 1 sample). This follow-up rate is consistent with prior longitudinal studies in military populations, ${ }^{14-17}$ and reflects the expected rotation of personnel in units during the first few months of returning home from deployment as well as the expected rotation of personnel in every unit over the course of a year. These numbers also reflect the number of soldiers who were available on any given assessment date owing to operational and training considerations.

As seen in Table 1, the longitudinal sample had a greater percentage of junior enlisted soldiers than the full time 1 sample and, accordingly, also had soldiers who were younger. Therefore, the primary analyses controlled for rank and age. The analyses also 
controlled for gender because previous studies have found that women are more likely to seek treatment than men. ${ }^{18}$ Data on ethnicity were not collected. Also reported in Table 1, the matched sample had slightly lower PTSD symptoms than the complete time 1 sample, but there was no significant difference on any of the four factors from the determinants of treatment-seeking items. Symptoms of PTSD were entered as a control variable in the primary analyses.

The variables we examined were a subset of those included in a larger programme assessing the effects of combat on the psychological and physical health of service members (overall Land Combat Study methods are published elsewhere)., ${ }^{2,19}$ Perception of a mental health problem at time 1 was assessed with an item asking whether the individual was currently experiencing a stress, emotional, alcohol or family problem. Response options were 'no', 'mild', 'moderate' or 'severe' and the variable was recoded into participants either not reporting a problem or reporting a problem of any severity. Symptoms of PTSD were measured using the 17-item PTSD Checklist. ${ }^{20}$ The scale was scored using 50 and the diagnostic algorithm for each cluster as the cut-off. ${ }^{2}$ Depression symptoms were measured using the nine-item Patient Health Questionnaire for depression, ${ }^{21}$ scored with four response options ('not at all' to 'nearly every day'). The cut-off score was determined by endorsing at least five of nine symptoms, including 'feeling down, depressed or hopeless' or 'having little interest in doing things', at least more than half the days in the past month and endorsing that these symptoms made it at least 'very' difficult to 'do their work, take care of things at home, or get along with other people'. Anxiety was measured using the seven-item Generalized Anxiety Disorder scale, ${ }^{22}$ scored with four response options $(0=$ not at all, to $3=$ nearly every day); the items were summed and cut-off determined by a cumulative score of 10 or greater and endorsing that symptoms made it at least 'very' difficult to 'do their work, take care of things at home, or get along with other people'. Details of cut-off score determination for the depression and anxiety measures have been previously reported. ${ }^{11}$

Treatment-seeking attitudes were measured at time 1 and time 2. There were 26 items, including 11 items from Hoge et $a l,{ }^{2} 6$ additional items from Kim et $a l,{ }^{1,15}$ and 9 items developed for this study to refine the negative attitudes factor reported by Kim et al. Items were scored with five response options ( $1=$ strongly disagree, to $5=$ strongly agree). Treatment-seeking was assessed at time 2 through the question, 'Approximately how many total visits with a mental health professional have you had in the past year?' with responses ranging from 0 to 12 . For this study treatmentseeking was coded as the participant reporting no visit (no) or one or more visits (yes). All analyses were carried out in SPSS version 22 on Windows.

\section{Results}

Table 1 provides a comparison of key demographic data and study variables for the sample assessed at both time 1 and time 2 with the overall time 1 sample.

\section{Factor analysis of time 1 data}

A factor analysis, using the complete time 1 sample data and conducted with the 26 treatment-seeking attitude items, suggested the existence of four factors (scree plot inspection; eigenvalues $>1$ ). Following a varimax rotation with a four-factor solution, three items were removed because of double loading. The remaining items and their loadings on the four factors are listed in Table 2. The four factors were concerns over professional impact, which reflected traditional perceived stigma items (Cronbach's $\alpha=0.96$ ); self-management, reflecting a preference for handling mental health problems oneself ( $\alpha=0.92)$; practical organisational barriers $(\alpha=0.90)$; and positive attitudes toward treatment $(\alpha=0.90)$. One item was removed because it was not conceptually consistent with the factor: ${ }^{23}$ specifically, the item 'I do not trust mental health professionals' was not included in the factor labelled 'self-management' because it addressed negative attitudes toward providers rather than a preference for selfmanagement. This item was the lowest loading item on the factor and also loaded above 0.30 on two additional factors.

\section{Predictors of seeking treatment at time 2}

In order to examine the factors at time 1 as predictors of seeking treatment at time 2, we conducted a series of logistic regressions. These regressions were conducted only for the 160 soldiers in the matched sample who at time 1 had screened positive for PTSD, depression or anxiety, or who had reported that they were currently experiencing a stress, emotional, alcohol or family problem. In order to avoid overadjustment in the logistic regression, we first ran a model that contained the demographic covariates of rank, age and gender at time 1, as well as PTSD symptoms at time 1 , as predictors of treatment-seeking at time 2. We included symptoms of PTSD, the most common problem reported, to control for degree of mental health problems in examining the impact of the factors on subsequent reported mental healthcare use. The results of this model are presented in the first column of Table 3, and indicate that the demographic variables were not predictive of treatment-seeking, whereas higher levels of PTSD symptoms at time 1 were associated with a higher likelihood of having mental health treatment at time 2 (Wald $\chi^{2}=11.52$, d.f. $=1, P<0.01$, odds ratio 1.05$)$.

In model 2, each treatment-seeking factor at time 1 was entered individually as a predictor of treatment-seeking at time 2, controlling for the demographic variables and PTSD symptoms at time 1 . The results of these logistic regressions are presented in the second column of Table 3, and reveal that when considered

Table 1 Demographic characteristics of the full time 1 and longitudinal samples

\begin{tabular}{|lcc|} 
& $\begin{array}{c}\text { Initial sample } \\
\text { (time } 1 \text { only) }\end{array}$ & $\begin{array}{c}\text { Longitudinal } \\
\text { sample } \\
\text { (times } 1 \text { and 2) }\end{array}$ \\
\hline Rank, $n(\%)^{*}$ & & \\
E1-E4 & $1323(57)$ & $348(69)$ \\
E5-E9 & $757(32.5)$ & $119(24)$ \\
Officers & $246(10.6)$ & $40(8)$ \\
\hline Gender, $n$ (\%) & & \\
Male & $2135(92)$ & $481(94)$ \\
Female & $186(8)$ & $31(6)$ \\
\hline Age (years), $n$ (\%)* & $54(2)$ & $34(6.6)$ \\
18-19 & $959(41)$ & $226(44)$ \\
$20-24$ & $707(30)$ & $136(26)$ \\
25-29 & $521(22)$ & $101(19.5)$ \\
30-39 & $113(5)$ & $20(4)$ \\
40 or older & & \\
\hline Scores: mean (s.d.) & $29.57(13.46)$ & $27.07(11.97)$ \\
PTSD symptoms* & $2.46(1.12)$ & $2.39(1.10)$ \\
Professional concerns & $1.85(0.86)$ & $1.84(0.84)$ \\
Practical barriers & $2.64(1.04)$ & $2.61(1.05)$ \\
Self-management & $3.12(1.31)$ & $3.03(1.31)$ \\
Positive attitudes & & \\
PTSD, post-traumatic stress disorder. & & \\
$*$ P $<0.05$. & & \\
\hline
\end{tabular}


Table 2 Factor loadings for treatment-seeking determinants items at time $1(n=2556)$

\begin{tabular}{|c|c|c|c|c|}
\hline \multirow[b]{2}{*}{ Item } & \multicolumn{4}{|c|}{ Factor $^{\mathrm{a}}$} \\
\hline & 1 & 2 & 3 & 4 \\
\hline It would be too embarrassing ${ }^{b}$ & 0.76 & 0.30 & 0.25 & 0.11 \\
\hline It would harm my career ${ }^{\mathrm{b}}$ & 0.83 & 0.25 & 0.22 & 0.11 \\
\hline Members of my unit might have less confidence in $m \mathrm{e}^{\mathrm{b}}$ & 0.86 & 0.22 & 0.18 & 0.14 \\
\hline My unit membership might treat me differently ${ }^{b}$ & 0.83 & 0.19 & 0.22 & 0.12 \\
\hline My leaders would blame me for the problem ${ }^{b}$ & 0.81 & 0.19 & 0.30 & 0.08 \\
\hline I would be seen as weak ${ }^{\mathrm{b}}$ & 0.87 & 0.25 & 0.17 & 0.15 \\
\hline It could hurt my chances of deploying & 0.61 & 0.25 & 0.36 & 0.05 \\
\hline It might affect my security clearance ${ }^{\mathrm{C}}$ & 0.73 & 0.25 & 0.27 & 0.11 \\
\hline I do not trust mental health professionals ${ }^{\mathrm{b}}$ & 0.33 & 0.56 & 0.35 & 0.05 \\
\hline Getting mental health treatment should be a last resort ${ }^{\mathrm{C}}$ & 0.30 & 0.69 & 0.24 & 0.04 \\
\hline There is sufficient information available for people to be able to help themselves & 0.22 & 0.64 & 0.25 & 0.20 \\
\hline I know how to help myself & 0.13 & 0.77 & 0.05 & 0.29 \\
\hline Strong people can resolve psychological problems by themselves & 0.21 & 0.79 & 0.20 & 0.09 \\
\hline I would prefer to manage problems on my own & 0.20 & 0.82 & 0.05 & 0.27 \\
\hline I would rather get information on how to deal with the problem on my own & 0.22 & 0.74 & 0.11 & 0.26 \\
\hline I do not know where to get help $p^{b}$ & 0.17 & 0.15 & 0.85 & 0.00 \\
\hline I do not have adequate transportation ${ }^{\mathrm{b}}$ & 0.19 & 0.15 & 0.77 & -0.01 \\
\hline It is difficult to schedule an appointment ${ }^{b}$ & 0.29 & 0.11 & 0.74 & 0.13 \\
\hline Mental health services are not available ${ }^{c}$ & 0.13 & 0.16 & 0.87 & -0.01 \\
\hline My workload does not allow time for treatment & 0.39 & 0.19 & 0.65 & 0.16 \\
\hline It takes courage to get treatment for a mental health problem & 0.20 & 0.29 & 0.07 & 0.84 \\
\hline Mental health counselling can be helpful for those who need it & 0.23 & 0.31 & 0.07 & 0.76 \\
\hline
\end{tabular}

individually, self-management was associated with a decreased likelihood of seeking treatment at time $2\left(\chi^{2}=3.89\right.$, d.f. $=1$, $P<0.05, \mathrm{OR}=0.64)$ and positive attitudes were associated with an increased likelihood of seeking treatment $\left(\chi^{2}=13.00\right.$, d.f. $=1$, $P<0.01, \mathrm{OR}=1.69)$. In contrast, professional stigma and practical operational barriers did not predict treatment-seeking at time 2 when entered individually.

Given the finding that self-management and positive attitudes each individually predicted treatment-seeking at time 2 , a third model was evaluated in which both self-management and positive attitudes were entered together as predictors of treatment-seeking at time 2 while controlling for the demographic covariates and PTSD symptoms at time 1 . As seen in the third column of Table
3, self-management continued to be associated with a reduced likelihood of seeking mental health treatment at time 2 $\left(\chi^{2}=11.02\right.$, d.f. $\left.=1, P<0.01, \mathrm{OR}=0.38\right)$ and positive attitudes continued to be associated with an increased likelihood of treatment-seeking $\left(\chi^{2}=11.52\right.$, d.f. $\left.=1, P<0.01, \mathrm{OR}=2.34\right)$. These results indicate that self-management and positive attitudes each independently predicted treatment-seeking at time 2 .

\section{Discussion}

In a longitudinal study of soldiers following deployment, two factors reflecting attitudes toward mental healthcare significantly

\begin{tabular}{|c|c|c|c|}
\hline \multirow[b]{2}{*}{ Variable } & \multicolumn{3}{|c|}{ OR $(95 \% \mathrm{Cl})$} \\
\hline & Model 1 & Model $2^{\mathrm{a}}$ & Model $3^{b}$ \\
\hline $\mathrm{Age}^{\mathrm{C}}$ & \multicolumn{3}{|l|}{$0.45(0.08-2.53)$} \\
\hline Gender $^{d}$ & \multicolumn{3}{|l|}{$1.69(0.39-7.44)$} \\
\hline Rank $^{\mathrm{e}}$ & \multicolumn{3}{|l|}{$0.16(0.03-0.82)^{*}$} \\
\hline PTSD symptoms & \multicolumn{3}{|l|}{$1.05(1.02-1.08)$} \\
\hline Professional concerns & \multicolumn{3}{|c|}{$0.96(0.65-1.43)$} \\
\hline Practical barriers & \multicolumn{3}{|c|}{$1.09(0.70-1.71)$} \\
\hline Self-management & & $0.64(0.42-1.00)^{*}$ & $0.38(0.21-0.67)^{\star *}$ \\
\hline Positive attitudes & & $1.69(1.10-2.57)^{\star *}$ & $2.34(1.47-3.72)^{\star \star}$ \\
\hline \multicolumn{4}{|c|}{$\begin{array}{l}\text { OR, odds ratio; PTSD, post-traumatic stress disorder. } \\
\text { a. Odds ratios in model } 2 \text { represent each variable entered individually, adjusted for age, gender, rank and PTSD symptoms at time } 1 . \\
\text { b. Odds ratios in model } 3 \text { represent values when self-management and positive attitudes were entered simultaneously, adjusted for gender, rank and PTSD symptoms at time } 1 . \\
\text { c. Age assessed using five dummy-coded variables; value represents contrast with highest OR. } \\
\text { d. Female gender coded as } 1 \text {. } \\
\text { e. Assessed using three dummy-coded variables; value represents contrast with highest OR. } \\
{ }^{*} P<0.05,{ }^{*} P<0.01 \text {. }\end{array}$} \\
\hline
\end{tabular}


predicted treatment-seeking. As predicted, self-management - or the preference for managing problems on one's own - was correlated with less treatment-seeking over time. In contrast, positive attitudes, or the belief that counselling is helpful and takes courage, were associated with an increased likelihood of treatment-seeking over time. These results underscore the point that understanding the decision to seek mental healthcare in the military is not necessarily served by an exclusive focus on traditional measures of stigma and practical organisational barriers to care. Instead, the gap between mental health problems and using mental healthcare appears to arise from conflict between perceiving oneself as capable and competent (i.e. able to handle problems on one's own) and approaching an expert for mental health treatment. This gap appears to be widened by a lack of confidence in the usefulness of such treatment. Although stigma is certainly reported by many soldiers, it is not stigma or practical barriers that appear to impede their accessing mental healthcare. Furthermore, positive attitudes toward the efficacy of treatment are also an important factor in determining treatment-seeking, suggesting the importance of not only portraying individuals seeking treatment as courageous and responsible, but also generating confidence in mental health treatment efficacy.

\section{Limitations}

There are some limitations to the study that need to be addressed. First, the list of treatment-seeking attitudes was not comprehensive. Although this list builds on the work of previous researchers, ${ }^{2,11}$ there are other topics that need to be included in order to be more comprehensive. A recent analysis of focus groups with soldiers, including those who sought mental health treatment, documented additional barriers and facilitators of treatment-seeking. ${ }^{24}$ These additional items included concerns about treatment affecting operational readiness, psychiatric medications, discomfort discussing mental health problems, positive leader behaviours and witnessing other treatment-seekers' experiences. This work, supported by our findings, can guide follow-on studies to examine more specifically how individual, peer and leader attitudes predict mental health treatment-seeking. Second, the item measuring mental healthcare utilisation was a self-report measure. Although some archived measure of military data would be potentially more objective, relying on an army database is also problematic. In the USA there are options for military mental healthcare that are not registered in any archived data-set. Specifically, the US Military Family Life Program offers free and unrecorded counselling visits with military and family life consultants, and Military OneSource (www.militaryonesource.mil) allows for 12 free and unrecorded mental health treatment visits per designated problem. Thus, self-reported visits are likely to be a more accurate measure of mental healthcare use. Third, the study is based on feedback from a large sample of soldiers returning from combat. It may be that the deployment cycle influences attitudes toward mental health treatment. As has been reported in the UK, service personnel returning from a combat deployment tend to be less concerned about stigma-related problems in deciding to pursue mental healthcare than those who are currently deployed. ${ }^{25}$ Thus, studies should consider the question of deployment cycle when addressing these issues. Fourth, attrition was high, introducing the possibility of bias or limited generalisability. Nevertheless, this attrition is to be expected given typical relocation rates in the military, and not indicative of systematic bias. Also, there were few differences among those who responded to the time 1 survey only and those who responded to both surveys. Moreover, control variables were used in the regression analyses to minimise the influence of any potential bias. Although the findings should be replicated with other samples, it is unlikely that differences between the initial time 1 sample and the matched sample could have accounted for the results obtained.

\section{Future research}

Future research should consider the degree to which the focus on self-management is specific to the occupational culture of the military or other high-risk occupational groups. There may be self-selection such that individuals who are highly motivated to keep themselves physically and psychologically fit may be more likely to join the military and those who do join may be motivated to sustain this fitness so that they can continue to serve. Although the results of the US National Comorbidity Survey suggest that this preference for self-management extends beyond the military, ${ }^{8}$ a more direct test should be conducted. In addition, it is not clear how these results apply to nations other than the USA, given that some previous work has documented national differences, ${ }^{26}$ whereas other studies have underscored similarities across armed forces. ${ }^{27,28}$ Although significant efforts in psychoeducation, resilience training and peer support have been made in the military and in other high-risk occupational settings, ${ }^{14,29-33}$ the gap in help-seeking for individuals with mental health problems remains a challenge. One of the most important implications of our findings is that the platform for delivering traditional mental health should be re-examined to take advantage of the preference for self-management. Future research should systematically examine what is meant by self-management, including qualitative methodology. ${ }^{1}$ It may be that the underlying principle of selfmanagement reflects a preference for maintaining a sense of self-efficacy in addressing salient life problems. ${ }^{34}$ Perhaps individuals believe that seeking help from others would undermine this sense of self-efficacy. Alternatively, perhaps individuals are motivated by self-management because seeking professional help would not be worth the physical or mental effort. Such a perspective could reflect a conservation of resources model. ${ }^{35} \mathrm{~A}$ third possibility is that self-management reflects a preference for reaching out to close others, peers and family, as suggested by Jones et al. ${ }^{7}$ In order to understand the selfmanagement preference, it would be useful to examine the extent to which the same preference drives decisions to seek out care for physical health problems, as well as help with problems more generally. ${ }^{36}$

\section{Study implications}

Results from our study may indicate that instead of a system in which providers see individuals who are willing to be identified as patients, a system of proactive mental health training should be developed. Such a system could involve direct outreach, coaching and packaging of information as self-development material in order to effectively leverage the preference for selfmanagement. Embedding mental healthcare at the unit level provides one such example. ${ }^{37}$ Furthermore, the results of studies showing that mental healthcare is effective in reducing symptoms and improving functioning at home and work should be communicated through training and public health announcements. Examples of choosing treatment as a reflection of courage can also support positive attitudes toward treatment-seeking. Taken together, such information could leverage the influence of attitudes to support the health and adjustment of individuals with mental health problems. 
Amy B. Adler, PhD, Military Psychiatry Branch, Center for Military Psychiatry and Neuroscience, Walter Reed Army Institute of Research, Silver Spring, Maryland; Thomas W. Britt, PhD, Department of Psychology, Clemson University, Clemson, South Carolina; Lyndon A. Riviere, PhD, Paul Y. Kim, MA, Walter Reed Army Institute of Research, Department of Military Psychiatry, Silver Spring, Maryland, USA Jeffrey L. Thomas, PhD, US Army Medical Research Unit - Europe, Walter Reed Army Institute of Research, Sembach/Heuberg, Germany

Correspondence: Dr Amy B. Adler, Military Psychiatry Branch, Center for Military Psychiatry and Neuroscience, Walter Reed Army Institute of Research, 503 Robert Grant Avenue, Silver Spring, MD 20910, USA. Email: amy.b.adler.civ@mail.mi

First received 14 Feb 2014, final revision 26 Sep 2014, accepted 7 Oct 2014

\section{Acknowledgement}

Thanks to the Land Combat Study team for their work in collecting, processing and managing the data.

\section{Funding}

Funding was received from the US Army Military Operational Medicine Research Program. The views expressed in this article are those of the authors and do not necessarily represent the official policy or position of the US Army Medical Command or the US Army. The study was approved by the Institutional Review Board at the Walter Reed Army Institute of Research.

\section{References}

1 Finnegan AP, Finnegan SE, Thomas M, Deahl M, Simpson RG, Ashford R. The presentation of depression in the British army. Nurse Educ Today 2014; 34 83-91.

2 Hoge CW, Castro CA, Messer SC, McGurk D, Cotting DI, Koffman RL. Comba duty in Iraq and Afghanistan, mental health problems, and barriers to care. N Engl J Med 2004; 351: 13-22.

3 Britt TW, Greene-Shortridge TM, Brink S, Nguyen QB, Rath J, Cox AL, et al. Perceived stigma and barriers to care for psychological treatment: implications for reactions to stressors in different contexts. J Soc Clin Psychol 2008; 27: 317-35.

4 Gould M, Adler A, Zamorski M, Castro C, Hanily N, Steele N, et al. Do stigma and other perceived barriers to mental health care differ across Armed Forces? J R Soc Med 2010; 103: 148-56.

5 Jones N, Mitchell P, Clack J, Fertout M, Fear NT, Wessely S, et al. Mental health and psychological support in UK armed forces personnel deployed to Afghanistan in 2010 and 2011. Br J Psychiatry 2014; 204: 157-62.

6 Greene-Shortridge TM, Britt TW, Castro CA. The stigma of mental health problems in the military. Mil Med 2007; 172: 157-61.

7 Jones N, Twardzicki M, Fertout M, Jackson T, Greenberg N. Mental health, stigmatising beliefs, barriers to care and help-seeking in a non-deployed sample of UK army personnel. J Psychol Psychother 2013; 3: 129.

8 Mojtabai R, Olfson M, Sampson NA, Jin R, Druss B, Wang PS, et al. Barriers to mental health treatment: results from the National Comorbidity Survey Replication. Psychol Med 2011; 41: 1751-61.

9 Department of National Defence. 2008/2009 Health and Lifestyle Information Survey: Regular Forces Report. Government of Canada, 2010.

10 Hoge CW, Grossman SH, Auchterlonie JL, Riviere LA, Milliken CS, Wilk JE. PTSD treatment for soldiers after returning from Afghanistan: low utilisation of mental health services and reasons for dropping out of care. Psychiat Serv 2014; 65: 997-1004.

11 Kim PY, Britt TW, Klocko RP, Riviere LA, Adler AB. Stigma, negative attitudes about treatment, and utilization of mental health care among soldiers. Mil Psychol 2011; 23: 65-81.

12 Pietrzak RH, Johnson DC, Goldstein MB, Malley JC, Southwick SM. Perceived stigma and barriers to mental health care utilization among OEF-OIF veterans. Psychiatr Serv 2009; 60: 1118-22.
13 Momen N, Strychacz CP, Viirre E. Perceived stigma and barriers to mental health care in Marines attending the Combat Operational Stress Control program. Mil Med 2012; 177: 1143-8.

14 Adler AB, Bliese PD, McGurk D, Hoge CW, Castro CA. Battlemind debriefing and battlemind training as early interventions with soldiers returning from Iraq: randomization by platoon. J Consult Clin Psych 2009; 77: 928-40.

15 Garvey Wilson AL, Hoge CW, McGurk D, Thomas JL, Clark JC, Castro CA. Application of a new method for linking anonymous survey data in a population of soldiers returning from Iraq. Ann Epidemiol 2010; 20: 931-8.

16 Castro CA, Adler AB, McGurk D, Bliese PD. Mental health training with soldiers four months after returning from Iraq: randomization by platoon. J Trauma Stress 2012; 25: 376-83.

17 Adler AB, Litz BT, Castro CA, Suvak M, Thomas JL, Burrell L, et al. Group randomized trial of critical incident stress debriefing provided to US peacekeepers. J Trauma Stress 2008; 21: 253-63.

18 Galdas PM, Cheater F, Marshall P. Men and health help-seeking behaviour: literature review. J Adv Nurs 2005; 49: 616-23.

19 Thomas JL, Wilk JE, Riviere LA, McGurk D, Castro CA, Hoge CW. Prevalence of mental health problems and functional impairment among active component and National Guard soldiers 3 and 12 months following combat in Iraq. Arch Gen Psychiatry 2010; 67: 614-23.

20 Blanchard EB, Jones-Alexander J, Buckley TC, Forneris CA. Psychometric properties of the PTSD Checklist (PCL). Behav Res Ther 1996; 34: 669-73.

21 Kroenke K, Spitzer RL, Williams JB. The PHQ-9: validity of a brief depression severity measure. J Gen Intern Med 2001; 16: 606-13.

22 Spitzer RL, Kroenke K, Williams JB, Lowe B. A brief measure for assessing generalized anxiety disorder: the GAD-7. Arch Intern Med 2006; 166: 1092-7.

23 Devellis RF. Scale Development: Theory and Application (3 edn). Sage, 2011.

24 Zinzow HM, Britt TW, Pury CLS, Raymond MA, MCFadden AC, Burnette CM. Barriers and facilitators of mental health treatment seeking among activeduty army personnel. Mil Psychol 2013; 25: 514-35.

25 Osorio C, Jones N, Fertout M, Greenberg N. Perceptions of stigma and barriers to care among UK military personnel deployed to Afghanistan and Iraq. Anxiety Stress Coping 2013; 26: 539-57.

26 Sundin J, Fear NT, Iversen A, Rona RJ, Wessely S. PTSD after deployment to Iraq: conflicting rates, conflicting claims. Psychol Med 2010; 40: 367-82.

27 Sundin J, Herrell RK, Hoge CW, Fear NT, Adler AB, Greenberg N, et al. Mental health outcomes in US and UK military personnel returning from Iraq. Br J Psychiatry 2014; 204: 200-7.

28 Kok BC, Herrell RK, Thomas JL, Hoge CW. Posttraumatic stress disorder associated with combat service in Iraq or Afghanistan: reconciling prevalence differences between studies. J Nerv Ment Dis 2012; 200: 444-50.

29 Gould M, Greenberg N, Hetherton J. Stigma and the military: evaluation of a PTSD psychoeducational program. J Trauma Stress 2007; 20: 505-15.

30 Reivich KJ, Seligman ME, McBride S. Master resilience training in the US army. Am Psychol 2011; 66: 25-34.

31 Mulligan $\mathrm{K}$, Fear NT, Jones $\mathrm{N}$, Alvarez $\mathrm{H}$, Hull L, Naumann $\mathrm{U}$, et al. Postdeployment battlemind training for the U.K. armed forces: a cluster randomized controlled trial. J Consult Clin Psychol 2012; 80: 331-41.

32 Greenberg N, Langston V, Everitt B, Iversen A, Fear NT, Jones N, et al. A cluster randomized controlled trial to determine the efficacy of Trauma Risk Management (TRiM) in a military population. J Trauma Stress 2010; 23: 430-6.

33 Arnetz BB, Arble E, Backman L, Lynch A, Lublin A. Assessment of a prevention program for work-related stress among urban police officers. Int Arch Occup Environ Health 2013; 86: 79-88.

34 Bandura A. Self-efficacy: The Exercise of Control. Freeman, 1997.

35 Hobfoll SE. Social and psychological resources and adaptation. Rev Gen Psychol 2002; 6: 307-24.

36 Bamberger P. Employee help-seeking: antecedents, consequences and new insights for future research. In Research in Personnel and Human Resources Management, vol 28 (ed JJ Martocchio, H Liao): 49-98. Emerald Group, 2009.

37 Johnson WB. Mixed-agency dilemmas in military psychology. In Military Psychologists' Desk Reference (ed BA Moore, JE Barnett): 112-5. OUP, 2013. 